\title{
Delivering value in the healthcare sector through the lens of hybrid organizing
}

Citation for published version (APA):

Angeli, F., \& Westra, D. (2018). Delivering value in the healthcare sector through the lens of hybrid organizing. In R. Wilden, M. Garbuio, F. Angeli, \& D. Mascia (Eds.), Healthcare Entrepreneurship (1 ed., pp. 27-45). Routledge/Taylor \& Francis Group. https://doi.org/10.4324/9781315157993-2

Document status and date:

Published: 01/07/2018

DOI:

10.4324/9781315157993-2

Document Version:

Publisher's PDF, also known as Version of record

Document license:

Taverne

\section{Please check the document version of this publication:}

- A submitted manuscript is the version of the article upon submission and before peer-review. There can be important differences between the submitted version and the official published version of record.

People interested in the research are advised to contact the author for the final version of the publication, or visit the DOI to the publisher's website.

- The final author version and the galley proof are versions of the publication after peer review.

- The final published version features the final layout of the paper including the volume, issue and page numbers.

Link to publication

\footnotetext{
General rights rights.

- You may freely distribute the URL identifying the publication in the public portal. please follow below link for the End User Agreement:

www.umlib.nl/taverne-license

Take down policy

If you believe that this document breaches copyright please contact us at:

repository@maastrichtuniversity.nl

providing details and we will investigate your claim.
}

Copyright and moral rights for the publications made accessible in the public portal are retained by the authors and/or other copyright owners and it is a condition of accessing publications that users recognise and abide by the legal requirements associated with these

- Users may download and print one copy of any publication from the public portal for the purpose of private study or research.

- You may not further distribute the material or use it for any profit-making activity or commercial gain

If the publication is distributed under the terms of Article $25 \mathrm{fa}$ of the Dutch Copyright Act, indicated by the "Taverne" license above, 


\title{
2 Delivering Value in the Healthcare Sector Through the Lens of Hybrid Organizing
}

\author{
Federica Angeli and Daan Westra
}

\section{Introduction}

Value creation is a critical area of research in entrepreneurship research and in particular in the context of business model design (Teece, 2010). Here we want to take a step back and start by looking at the definition of value before delving into the typical issues of value in healthcare entrepreneurship.

The English Oxford Living Dictionary defines value as "the regard that something is held to deserve; the importance, worth, or usefulness of something." If we were to ask anybody in the world about what he/she values in life the most, "being healthy" is bound to be among the most frequently heard answers. If we would ask any politician about his/her agenda for the upcoming election, healthcare is bound to be an issue raised by many. In fact, most will agree that it is the sign of a developed nation to be able to provide citizens with universal access to healthcare. In other words, the importance of good health, and consequently highquality healthcare, is recognized by most people. Health and healthcare are thus of great value in modern day societies. Being a fundamental principle in healthcare, this chapter revolves around the concept of value. It is divided into two sections. In the first section, we explore the concept of value and value-based healthcare, providing the reader with a basic understanding of what it is and why it is of importance. In the second section, we shift our attention to value delivery by healthcare organizations and we will adopt the lens of hybrid organizations to understand how healthcare providers deliver value and what organizational challenges they face in doing so.

\section{An Introduction to Value}

While there might be consensus regarding the need and importance of good health and high-quality healthcare, there is less agreement regarding the matter of how to operationalize both of these concepts. Or, in other words, there is less agreement on what actually constitutes health 


\section{Federica Angeli and Daan Westra}

and high-quality healthcare. Larson (1999) has, for example, identified four different models of health: the medical model, the World Health Organization (WHO) model, the wellness model, and the environmental model. In the medical model, health is considered the absence of disease. In the WHO model, health is a state of complete physical, mental, and social wellbeing. In the wellness model, health equals optimal personal fitness for full, fruitful, creative living. In the environmental model, health is defined as the ability of an organism to maintain a balance with its environment, with relative freedom from pain, disabilities, or limitations, including social abilities. The debate surrounding the definition of health has not stopped at these four models. More recently, scholars have once again critiqued the existing models of defining health, arguing that they are insufficiently aligned with the increasing prevalence of chronic diseases, and with the ability of chronic patients to cope with the disease and conduct a socially, physically, and mentally fulfilling life. Huber et al. (2011) have consequently defined health as "the ability of patients to adapt and self-manage," therefore emphasizing to the quality of "resilience or capacity to cope, maintain and restore one's integrity, equilibrium, and sense of wellbeing" (Huber et al., 2011: 344). We therefore identify Huber's definition as the "resilience model." It is clear that each of these models operationalizes health in different ways, ranging from a rather narrow and physical definition in the medical model, to a broad and more all-encompassing definition in the environmental model and the model presented by Huber and colleagues. While health might be considered of the utmost importance to many people, they can have vastly different perceptions as to what it is that they actually find important. Table 2.1 reports the main perspectives on the concept of health, and related definitions.

Similar to the various ways of defining health, there is a plethora of indicators that have the ambition to measure quality of healthcare. The academic literature on this topic is vast and different measures have

Table 2.1 Definitions of Health. Adapted from Larson (1999)

Model Definition

1. Medical model

2. World Health Organization (WHO) model

3. Wellness model

4. Environmental model

5. Resilience model
The absence of disease or disability

State of complete physical, mental, and social wellbeing, and not merely the absence of disease or infirmity

Health promotion and progress toward higher functioning, energy, comfort, and integration of mind, body, and spirit Adaptation to physical and social surroundings- - a balance free from undue pain, discomfort, or disability

Ability of patients to adapt and self-manage 
surfaced for different segments of the healthcare sector, and at different levels. Examples range from clinical measures related to specific diseases to generic measures such as safety, satisfaction, and quality of life at the patient level; to measures such as readmission rates to examine quality of care at the level of healthcare organizations, and ultimately to international, aggregated rankings measuring the effectiveness and efficiency of whole healthcare systems (such as the Euro Health Consumers Index, or the Bloomberg ranking for healthcare systems). For some of these indicators, a range of measurement instruments have been developed. The Dutch Healthcare Inspectorate publishes annually more than 1,000 indicators to rank hospitals according to the quality of care delivered, at condition, specialty, and hospital level. In this mare magnum of metrics, the most common distinction regarding quality of care indicators relates to structure, process, and outcome indicators introduced by Donabedian (1988). The notions of measuring structure and process indicators are that they ultimately constitute a prerequisite to generating positive health outcomes for patients.

Operationalizing health and high-quality healthcare is only one side of the value equation, however. That is, most economists will define value not only as how the quality or usefulness of a given product or service, but rather as the amount of money a consumer is willing to pay for that good or a service. In other words, value ultimately depends on the wants and needs of consumers. Having established that most people want, and in many cases need, high-quality healthcare services, value in the healthcare sector should thus consider the monetary worth of these services. Despite the widespread academic debate surrounding the definition of health and the way in which quality of healthcare is best operationalized, the concept of value in healthcare has remained relatively under-debated for quite some time. The concept had received attention from scholars in the field of economic evaluations, in which interventions are typically compared based on their relative cost-effectiveness, in journals such as Value in Health, the official journal of the International Society for Pharmacoeconomics and Outcomes Research (ISPOR). However, it was not until the economist Michael Porter argued that value in healthcare remained largely misunderstood and formally defined the concept as "health outcomes achieved per dollar spent" (Porter, 2010: 2477) that value-based healthcare became arguably one of the most talked-about concepts in the realm of health policy and management.

The concept of value in healthcare formalized by Porter (2010) illustrates the inherent interrelation between outcomes and costs. So much so, that he equates value to efficiency and states that competition is considered the most appropriate way to maximize value (Porter and Teisberg, 2004) (see Chapter 3 for more on competition in the healthcare sector). He states that improving value should constitute the goal of stakeholders 
in the healthcare sector. In his paper, Porter furthermore takes several clear stances surrounding value and the interrelation between costs and outcomes (i.e., quality) in the healthcare sector. First, he posits that value can and should only be defined around the patient, making all activities, products and processes, which do not have value for the patient superfluous. Second, he argues that value cannot be measured at the level of one organization, as the creation and delivery of healthcare inherently transcends organizational boundaries (see also Chapter 6 on open innovation in healthcare). Consequently, both costs and outcomes should be measured across the full range of care pathway. Third, Porter argues that the focus should be on outcome indicators, rather than on structure or process indicators.

Although Porter was not the first to note that outcomes are what ultimately matter to patients, notable health economists have long indicated that it is difficult for patients to assess the quality of the outcome of medical treatments (Arrow, 1963; Dranove and White, 1994). In his description of value in healthcare, Porter concedes that outcomes are indeed seldom collected rigorously and systematically. Nonetheless, he describes so-called comprehensive outcome measures as useful in determining value in the healthcare sector. According to this line of reasoning, a single outcome measure is by definition inappropriate, as it is unable to capture all of the dimensions which patients consider relevant. In fact, some of the outcomes could even contradict one another. He considers it important to include both short-term and long-term outcome measures, and introduces a tiered hierarchy of outcome measures to define value. The first tier includes health outcomes such as survival and degree of recovery. The second tier focuses on the speed of recovery and the burden of the recovery process. The third and last tier assesses the long-term effects of the treatment and whether or not the attained health status is sustained over a prolonged period of time. Porter argues that, in order to define value in an appropriate way in the healthcare domain, there should be a set of tiered outcome measures for each medical condition.

The increased attention for the concept of value in healthcare, or value-based healthcare, over the past decade has not been confined to the realm of academics. Instead, it has made its way into practice in various forms. Perhaps the most notable of these are financial incentives introduced to improve the quality of care delivered by providers. Such schemes are known as pay-for-performance or value-based purchasing, and the US and UK are considered to be frontrunners in the adoption of these methods (Bonfrer et al., 2018). Under these schemes, those providers that offer services with the highest value to patients are contracted or receive additional payments. However, a recent study by Bonfrer et al. (2018) suggests that these incentives have only a very limited effect in terms of patient outcomes. The authors offer several explanations for this lack of value improvement. First, they note that the financial incentives 
are typically small. Second, they argue that value-based purchasing programs can be complex for providers. Third, the authors suggest that the fact that the financial gains were distributed once a year could have stifled quality improvements, as well. What this study shows is that even though providers and purchasers attempt to improve value of healthcare services, achieving this goal is not a straightforward process. It should be recognized that although patient outcomes remain the ultimate goal for all stakeholders in the healthcare domain, each organization faces peculiar challenges, based on its position in the market and specific business model. In particular, most healthcare providers faced inherent duality by negotiating with insurers/governments on service, while delivering these services to an entirely different target group: the patients. In the remainder of this chapter, we focus on healthcare providers, and shift our attention to the tensions arising from the co-existence within healthcare organizations of pressures towards both high service quality and financial efficiency. Specifically, we will refer to the literature and theories addressing hybrid organizations, which hold both a social and financial mission. We will then use this lens to understand the challenges faced by healthcare providers.

\section{Understanding Healthcare Providers Through the Lens of Hybrid Organizations}

A crucial decision of healthcare entrepreneurs and managers more generally is to decide on the business model and how to best structure their organization to maximize patients' value. The concept of value-based healthcare has placed the patients more central than ever before in the delivery of healthcare services and in the assessment of healthcare organizations' performance. This paradigm shift ensures that healthcare services and providers remain patient-centered and emphasizes the social responsibility of healthcare organizations. At the same time, the skyrocketing healthcare expenditures facing Western countries, and the consequent pro-competitive policy reforms introduced by several governments (e.g., Westra et al., 2015) produced increasing pressures towards efficiency and financial sustainability for healthcare providers. A tension between counteracting forces hence emerges. On the one side, value-based healthcare requires a strong focus on the patient, in the form of customized diagnostic and therapeutic services, highly responsive systems with enough capacity to deal (also) with emergency situations, but also ad hoc multidisciplinary teams for complex conditions, and innovative (technological) solutions to ensure better quality of life, for example, to elderly and chronic patients. On the other side, the transition towards more valueand patient-oriented models needs to happen with fewer resources, and hence more efficient organizational processes, technologies, and organizational models, to contain otherwise unsustainable healthcare costs. The 


\section{Federica Angeli and Daan Westra}

deriving tensions and challenges can be fierce, and the need for entrepreneurs and intrapreneurs to drive technological as well organizational innovation in the healthcare sector is unparalleled and higher than ever before.

\section{Hybrid Organizations}

The lens of hybrid organizations is very suitable to develop an understanding of how healthcare entrepreneurs face counteracting institutional forces, which result in conflicting institutional logics. Hybrid organizations pursue a social mission while using a commercial business model; therefore, they present entrenched duality, in the form of coexisting socially oriented values as well as profit-oriented processes and competencies (Santos et al., 2015). Hybrid organizational forms are often found to complement governments and third sector organizations in tackling complex social challenges, because of their unique capabilities to scale up and develop long-term action through self-sustained models. These organizations hence transcend the profit/non-profit differentiation, blurring the boundary between business and charity (Battilana and Lee, 2014; Haigh et al., 2015), while attempting to reconcile private interests and public good.

Santos et al. (2015) note how hybrid organizations flourish particularly in market segments where value spillover is contingent on organizational actions and where transactions are hindered by demand-side obstacles, for example, inability to pay or access the product, or unwillingness to pay because of lack of awareness about the benefits. Value spillover is a crucial notion to understand hybrid organizing. In some cases, the value spillover-namely, the social benefit for the organizations' beneficiariesoccurs naturally and automatically when one of the services or products is delivered. Providing electricity generators or health check-ups in urban slum settings constitute examples of products and services which have an immediate and visible use, the value of which is immediately recognized by the communities. In other cases, the value spillover is instead contingent on organizational actions. Santos et al. (2015) provide the example of microfinance, which delivers social values only if the lenders employ the money to start up commercial activities and to generate for themselves and for the communities. Hence, mentoring activities are often necessary to ensure that the microloans achieve their social potential. Another example is provided by the French work integration social enterprises (WISEs) explored by various authors (Battilana et al., 2015; Pache and Santos, 2013). A WISE's social goal is to reduce long-term unemployment by helping individuals with a disadvantaged background to re-enter the job market. WISEs therefore hire unemployed people for two years, and produce goods or services such as gardening or recycling that are then sold in the free market (Battilana et al., 2015). The ultimate 
social benefit is to requalify the skills and experience of the long-term unemployed to create new (stable) job opportunities for them. In order for this long-term social mission to be achieved, in addition to the work experience offered by WISE, these disadvantaged groups also need to be supported by coaching, training, and mentoring services, to be able to fully re-entered the market with their newly acquired competencies.

Another core feature of hybrid organizations relates to the degree of overlap between customers-individuals or entities that pay for the organizations' commercial services-and beneficiaries, who identify the target group of the organization's social activities (Santos et al., 2015). The previously cited case of WISEs illustrates a situation in which customers do not overlap with beneficiaries. The target group of WISEs' social activities (the unemployed) is in fact disconnected from WISEs' customers (the individuals who buy products/services). Another example is the widespread model of non-government organizations (NGOs), who provide services to disadvantaged communities (the beneficiaries) through the funding provided by donor agencies worldwide, which can then be seen as the NGOs' customers, as income generators. Finally, a third noteworthy illustration is provided by the many business models relying on customers' cross-subsidization, a well-known mechanism to achieve sustainable business models for inclusive healthcare delivery (Angeli and Jaiswal, 2016). Examples are known in healthcare models, for example, in the case of Aravind Eye Care, a world-renowned eye hospital that operates in India and charges the full fee for eye surgery to wealthy patients (customers) and partially uses the consequent profit margin to cover healthcare costs of low-income individuals (beneficiaries). Such examples can also be appreciated in sectors that are becoming more socially aware, with models that attach a donation with each product purchase. It is the case of Tom-a famous brand of espadrilles shoes-which has established a just as famous philanthropic model of buy one/give one, in which each purchase subsidizes a pair of shoes for a child living in poverty around the world.

Based on these two dimensions, value spillover and overlap between customers and beneficiaries, Santos et al. (2015) developed a typology of organizational hybrids. The four types-namely Market hybrids, Bridging hybrids, Blending hybrids, and Coupling hybrids—-present important differences that are likely to profoundly affect their structure, missions, leadership style, degree of professionalization, inter-organizational partnerships, relationship with governmental agencies, etc. (Battilana and Lee, 2014). While investigating challenges faced by hybrid organizations, several studies have particularly focused on coupling hybrids, which represent the most complex and fragile category of business models. Social and financial logics are often difficult to balance, requiring opposing organizational actions, clashing allocation of resources, and different human resources strategies. Evidence proves that social imprinting does 


\section{Federica Angeli and Daan Westra}

depress economic productivity (Battilana et al., 2015). The difficult act of balancing conflicting institutional logics can lead such organizations to paralyze or even perish over time (Pache and Santos, 2013; Tracey and Jarvis, 2006), and poses a substantial risk of mission drift and loss of organizational identity (Battilana and Dorado, 2010). Constant alignment and attention posed to design structures, governance mechanisms, and human resource management systems are crucial to overcome such challenges (Santos et al., 2015). Fosfuri et al. (2016) have added to this supply-side perspective a demand-side perspective, highlighting how the necessity to scale up through intra-industry growth may compromise customers' identification by diluting the product symbolic value, thereby undermining legitimacy.

We argue here that these four organizational types can fruitfully inform the understanding of healthcare organizations. Because this typology has proven extremely valuable to the understanding of social enterprises, it can shed new light on the understanding of the market positioning of entrepreneurial ventures in the healthcare sector. Figure 2.1 represents the typology developed by Santos et al. (2015) and applied to the healthcare sector.

\section{Healthcare Market Hybrids: The Case of Cardiovascular Care in India}

Market hybrids in healthcare are organizations that are able to transact with their patients as customers. The business model in this case is

$$
\text { Payers }=\text { patients } \quad \text { Payers }<>\text { patients }
$$

\begin{tabular}{|c|c|c|}
\hline $\begin{array}{l}\text { Automatic } \\
\text { value spillover }\end{array}$ & $\begin{array}{l}\text { Healthcare } \\
\text { Market hybrids }\end{array}$ & $\begin{array}{l}\text { Healthcare } \\
\text { Bridging hybrids }\end{array}$ \\
\hline & $\begin{array}{l}\text { Case: Indian } \\
\text { cardiovascular care- } \\
\text { Narayana Health }\end{array}$ & $\begin{array}{l}\text { Case: Dutch specialized } \\
\text { care-AzM }\end{array}$ \\
\hline $\begin{array}{l}\text { Contingent } \\
\text { value spillover }\end{array}$ & $\begin{array}{l}\text { Healthcare } \\
\text { Blending hybrids } \\
\text { Case: Health-enhancing } \\
\text { technologies among BoP- } \\
\text { Sulabh International }\end{array}$ & $\begin{array}{l}\text { Healthcare } \\
\text { Coupling hybrids } \\
\text { Case: Dutch mental } \\
\text { healthcare - Mondriaan }\end{array}$ \\
\hline
\end{tabular}

Figure 2.1 Hybrid Organizations Typology Applied to Healthcare Organizations 
relatively simple, as the social impact is achieved through a straightforward commercial formula, in which the patients pay directly for the care they receive. Santos et al. (2015) illustrate three main obstacles that hinder customers from being able to pay for services: inability to pay because of affordability issues; unwillingness to pay because of inability to recognize added value in the service/product, despite the actual benefit this would bring; and difficulty to access the product and services. These dimensions partially overlap with the aspects of affordability, awareness, availability, and acceptability to be considered when offering services and products to base-of-the-pyramid customers (Angeli and Jaiswal, 2015). Healthcare market hybrids are care providers that managed to create a type of service able to overcome patients' inability or unwillingness to pay for the service. It should also be noted, however, that most healthcare systems in industrialized countries strongly restrict direct (so-called out-of-pocket) patient payments for a large part of healthcare services, instead using thirdparty payers (governments or insurance companies) to mediate between patients and providers. The underpinning logic is to curb system-level healthcare costs, avoid catastrophic individual expenditures and reduce the cost of services by increasing bargaining power on the demand side. Within this systemic configuration, which allows in most countries for large and almost universal healthcare coverage, the space for healthcare market hybrids is limited. This type of model can be seen, for example, in Western countries in the area of elective or cosmetic care, which is typically not included in insurance packages. In emerging contexts however, where medical insurance systems are less developed, or in contexts where insurance coverage can be limited, such as the US, market hybrids can be present also for life-threatening conditions such cardiovascular diseases. It is the case of Narayana Hrudayalaya $(\mathrm{NH})$, a world-renowned heart hospital headquartered in Bangalore, India (Angeli and Jaiswal, 2016). $\mathrm{NH}$ has been able to develop a business formula that delivers heart surgery for $1 \%$ of the price of what it would cost in the US and EU, with comparable after-surgery infection and recovery rates. The average cost of a bypass surgery at NH is US $\$ 1,500$ (INR 99,000) in comparison with US $\$ 144,000$ in the US. NH's mortality and infection rates are $1.27 \%$ and $1 \%$, respectively, for coronary artery bypass graft operations, which are comparable to US hospitals. Part of the success is due to economies of scale, where volume drives down costs and speeds up learning curves, thereby improving quality. $\mathrm{NH}$ is a 1,000 -bed hospital in Bangalore that conducts on average 35 major heart surgeries per day and a maximum of 60 per day in its 24 operation theaters, making it one of the largest cardiac hospitals in the world. By contrast, the largest heart hospital in the UK has 270 beds and five operating theaters, and conducts 58 operations a week.

This is enabled by an "assembly line model," in which junior doctors do early stage tasks, which enables surgeons to do three surgeries a day instead of one. Human resource management is also important: in order 
to maintain the knowledge, attrition rate must be low. $\mathrm{NH}$ has an attrition rate close to zero, where personnel is strongly intrinsically motivated by "passion and compassion" 2 (Narayana Hrudayalaya Limited, 2016). The third important point is the savvy use of technology such as telemedicine, and strategic partnerships to suppliers. Founded in 2001 by Dr. Devi Prasad Shetty, by 2014, NH had 26 hospitals in 16 cities with 6,900 beds, 13,000 employees and 1,500 doctors (Angeli \& Jaiswal, 2016). Because of its striking performance indicators, NH has been object of wide media attention (e.g., Indian hospital series on the broadcaster Al Jazeera), as well as business cases and scholarly publications.

\section{Bridging Hybrids: The Case of Secondary Care in the Netherlands}

Bridging hybrid healthcare providers are those organizations delivering care treatments that have immediate and recognizable value for the patients (automatic value spillovers), who however do not overlap with the customers. These organizations, therefore, present a split between beneficiaries and payers. Most healthcare organizations in Western countries-where third payers are employed by healthcare systems to mediate between patients and providers-are bridging hybrids. Dutch hospitals, for example, deliver specialized care to patients (their beneficiaries) while receiving reimbursements from insurance companies. Since government-fixed prices (tariffs) for treatments have mostly been abolished in the Netherlands with the Health Insurance Act in 2006, a large share (the so-called "B segment," which currently comprises more than $70 \%$ of treatments) of prices for care delivered within the diagnostic-related group systems are subject to negotiation between care providers and (private) insurance companies (Schut \& Varkevisser, 2017). It is important to note that such negotiation process can present several complexities, especially in those cases where information asymmetry is high (e.g., rare diseases), when several co-morbidities are present (e.g., diabetes) and when long-term treatment is required (e.g., heart diseases).

The complexity created by the co-existence of multiple institutional logics is very tangible, and particularly evident in the Dutch healthcare system. It is perhaps most pronounced in the case of academic hospitals. Academic hospitals typically treat the most complex patients of a given population (e.g., patients with a specific disease or condition). While treating these complex patients is inherent to their role as teaching hospitals and research centers, the costs of treating these patients are typically higher than the costs of treating less complex patients in the same population. Consequently, the value spillover is largest for these beneficiaries, as they are treated by an organization equipped to do so when no other organization is. Yet, given the diagnosis-related groups (DRG)-like system used to pay healthcare providers in the Netherlands, academic hospitals are typically only reimbursed the standard rate per 
DRG, which constitutes the price paid for an "average" patient of a given population. The mismatch between the value delivered to patients and the monetary reimbursement received from third-party payers presents these organizations with a difficult balancing task of the competing logics of social value versus financial efficiency. The increasing number of independent treatment centers which have entered the market since the procompetitive reforms in the Netherlands (see Chapter 3 for more on that matter), are typically perceived as organizations following the inverse of this logic. That is, they are often accused of cherry-picking the easiest patients from a population and treating these against lower costs but while receiving the average per-DRG price from payers.

The introduction and expansion of the B-segment has exposed hospitals and care providers to substantial financial pressures, especially in relation to the high bargaining that the four major insurance groups enjoy in the Netherlands. This is often perceived as a constraint by specialists and hospitals at large, which find limited financial slack to invest in innovative medical technologies, and new business model innovations. Also, organizational resources and attention need to be shifted towards improving process efficiency and standardization, which is at times perceived as conflicting with the ad hoc nature of several segments of patient care, often requiring treatment customization and patient-centered, rather than disease-centered, approach. Finding the balance between financial performance and quality of care/patient satisfaction is perceived by clinicians and hospital managers to be difficult, especially when budget cuts are severe and require financial reassessment in a short span of time.

\section{Blending Hybrids: The Case of Health-Enhancing Technologies in Urban Slums}

Healthcare blending hybrids are those organizations who deliver services and products that have an immediate health benefit, which however fails to be recognized by the users, unless organizational efforts are devoted to increase awareness, discover value together with the users, and essentially co-create patient needs (Angeli and Jaiswal, 2016). Slum-dwellers present very idiosyncratic health-seeking behavior and perception on curative value of treatment and technologies, arising from a complex nexus of religion, gender, marital status, employment, ethnicity, and literacy level (Das et al., 2018). Interesting examples can be drawn from the case of health-enhancing product innovations, which private companies, governmental agencies, and NGOs alike have tried to introduce in disadvantaged, low-income settings. The fact that these technologies are not utilized, despite the wide improvement that they could produce in the health conditions of disadvantaged communities, is a well-known wicked problem in global health (Banerjee and Duflo, 2012). Idiosyncratic norms, values, and beliefs of target clients who live in poor conditions 
have to be carefully understood, to be able to successfully introduce new products and induce behavioral change.

Sulabh International is an enterprise that succeed where others failed: improving toilet use among slum-dwellers and rural poor (Angeli and Jaiswal, 2016). The problem of open-air defecation is widespread in India. In 2014, half of the Indian population did not have regular access to sanitation facilities, including toilets. This has important public health consequences, with more than 600,000 deaths yearly directly related to infectious diseases and diarrheic conditions spurred by unhealthy and bacteria-prone environments, as estimated by the World Health Organization report in 2014. However, individuals living in resource-constrained settings are often not fully aware of the health hazards related to open defecation. Instead, when toilets are installed in-house, their use is very limited because people are reluctant to dispose of human waste in the same restricted space where they also eat and sleep, a behavior that seems to be associated with lower castes, and with religious and socio-cultural beliefs (Mehrotra, 2014). In addition to that, free public toilets are often considered unhygienic and hence are seldom used (O'Reilly and Louiss, 2014). The interplay of the two trends results into a difficult-to-eradicate habit of slum-dwellers and rural villagers of defecating in the open, which compromises the health status of the communities and poses challenges to women's safety. Leveraging in-depth knowledge of these dynamics and of the socio-cultural context of the disadvantaged communities, Sulabh International successfully introduced pay-per-use public toilets, which charge a small amount for the use of common toilets outside homes. The affordable rate ensures cleanliness and for a small markup clients can enjoy a "service experience," which includes bath, laundry, and accommodation services. Because the public health importance of proper human waste disposal is not immediately evident for consumers, Sulabh International has engaged in a number of activities to raise awareness among the target communities. Sulabh International Institute of Health and Hygiene and the Sulabh International Museum of Toilets were specifically created to promote sanitation and hygiene and while training teachers, school children, volunteers, and associates involved in promoting hygienic practices. Sulabh International Institute of Health and Hygiene educated over 8,000 female workers towards creating awareness about the relationship between sanitation and health (Kumar Rastogi, 2013).

While Sulabh International represents a successful case of blending hybrids in the healthcare value chain, the history and evolution of blending hybrids is punctuated by challenges, especially that of creating a model that can incorporate the necessary financial lack to sustain health awareness campaigns. Improved cooking stoves that reduce toxic indoor pollution by using modern technologies and less polluting fuels still struggle to reach scale among urban slums and rural villages in emerging countries (Lewis and Pattanayak, 2012). 


\section{Coupling Hybrids: The Case of Dutch Mental Healthcare}

Coupling hybrid organizations are by far the most widely studied in the literature, as they present the highest level of complexity, risks of mission drifts, and difficulty of achieving financial sustainability and maintaining their legitimacy among the relevant stakeholders (Fosfuri et al., 2016). Along the two-dimensional typology developed by Santos et al. (2015), coupling hybrids are those organizations that witness a split between customers and beneficiaries and that deliver value that is contingent on organizational actions. In the healthcare domain, this translates into health providers that operate in a system that uses third-party payers and whose services do not have immediately observable value or whose value manifests in the longer term, and/or is complex to measure through immediate metrics. This is the case with mental healthcare organizations. Mental healthcare providers have the difficult task of delivering treatment that is often complex and long term for conditions that are often ambiguous, subjective, and highly idiosyncratic, both with inpatient and outpatient approaches, often struggling with patients' reluctance to treatment and tendency to deviate from the prescribed care pathway of therapy, in addition to patients' delayed care-seeking because of the stigma that is still associated with mental health issues (Westra et al., 2016). Furthermore, in the case of youth mental healthcare, the Netherlands has recently reformed its system to favor a more community-based perspective including multiple stakeholders, in inpatient as well as everyday settings, so that teachers, family members, and formal caregivers need to coordinate and collaborate for the treatment to be effective and long-lasting. However, disparate viewpoints and values held by multiple stakeholders often collide when defining the mental health policy problem and potential solutions, which brings mental healthcare to be increasingly seen as a "wicked problem" for policymakers (Hannigan and Coffey, 2011). For example, while community-based approaches have found support from many policymakers, some scholars argue that these might also be responsible for too much or too little monitoring of service users, by enforcing top-down solutions that factually offset the expected benefits of community-centered care (Hannigan and Coffey, 2011; Molodynski et al., 2010). Another point of fierce discussion relates to the dominant view in relation to what constitutes a preferred treatment trajectory, with the biomedical route being often favored over alternative, more therapybased care trajectories.

On the financing side, the mental healthcare sector has been undergoing major changes in most industrialized countries, with the UK and the Netherlands being prominent examples (Hannigan and Coffey, 2011; Westra et al., 2016). Worldwide, the incidence and relevance of mental healthcare conditions are rising steeply, along with increasing awareness of the previous large underestimation of the problem (Vigo et al., 
2016; World Health Organization, 2013). It is now estimated that the economic losses due to untreated mental disorders, in terms of lower productivity, lower employment rates, foregone taxes, and increased welfare costs amount to more than 10 billion days of lost work annually-the equivalent of US\$1 trillion per year (Chisholm et al., 2016). Between $76 \%$ and $85 \%$ of people in low-income and middle-income countries with severe mental disorders do not receive treatment, a percentage which ranges between $35 \%$ and $50 \%$ in high-income countries (World Health Organization, 2013). The reasons for this lie in the complex interplay of diagnosis-related stigma, lack of specialized workforce, lack and/or little understanding of the diseases, complexity of specialized treatment, and poor socio-economic conditions such as poverty, unemployment, poor housing, poor education, and substance abuse. Sadly, many young individuals also suffer from mental health disorders, with mental conditions accounting for a large share of illness affecting youth, and suicide being the second most common cause of death for young people worldwide (World Health Organization, 2013). Mirroring the trend, the incidence of mental healthcare issues is sharply on the rise also in the Netherlands, especially among the youth. More than 1 out of 5 Dutch youth has experienced a severe mental health episode by the age of 19 , and $75 \%$ of mental health conditions manifest before the age of $25,{ }^{3}$ complicated by the fact that young people on average wait longer before seeking help. ${ }^{4}$ And these numbers are rising. In 2016, $4 \%$ of young individuals declared to have suffered from depression for more than six months, more than double than in $2014 .{ }^{5}$ This poses the issue on how to best tackle the rising demand in a financially sustainable way. In this light, the Dutch mental healthcare sector has undergone various policy changes in several waves, with the idea being to promote (cheaper) outpatient-based, communitycentered business models, away from the institutionalization perspective that ruled in past centuries. The complex institutional environment, the difficult target segment, the challenges deriving from a shifting regulatory framework and from increasing financial pressure, and the difficulty of balancing multiple institutional logics arising from (clashing) interests of buyers and patients have resulted in the current critical situation of the Dutch mental healthcare sector. This is reflected in the severe financial situation of large incumbent mental healthcare providers in the Dutch landscape, with many providers producing losses or even going bankrupt in the past few years.

Mondriaan Mental Health Foundation constitutes an example of such a large incumbent provider. Mondriaan is a mental healthcare provider, which diagnoses and treats a wide range of mental health problems for children, youth, adults, and elderly in more than 40 locations. With 1,662 full-time equivalent (FTE) personnel, Mondriaan is one of the largest employers in Southern Limburg, and the organization treated approximately 11,000 patients in 2015. Although Mondriaan's presence in the 
mental health sector is wide and long-lasting, the organization had €136 million turnover in 2015, which amounts to a loss of $€ 2.6$ million, and failed to meet the bank's financial criteria. Recent and rapid market developments have contributed to Mondriaan's hardship. In particular, procompetitive regulation introduced in 2006 and then in 2014 specifically for mental healthcare services has opened up price negotiations between providers and insurance companies over specialized mental health care. This mechanism has increased external pressure on Mondriaan's operations, which currently face a difficult tension between cost-effectiveness and quality of care. Such tension reflects within the internal environment of the organizations, in balancing short-term vs. long-term solutions, and weighing the multifaceted perspectives offered by managers, specialists, board members, patients, and families. The specific structure of the market, with few medical insurance companies, and the increasing regulatory pressures towards the shift from (expensive) inpatient to (cheaper) outpatient care have created the need for a short-term rethinking of Mondriaan's business model. However, the size and the tenure of the organization in the market constitute important inertial factors. To add complexity, the Child and Youth section of Mondriaan, which targets patients in the 0-23 years old age range, has undergone specific regulatory changes and faces peculiar challenges. The child and youth care segment of mental healthcare has been moved to the youth act, shifting the responsibility for purchasing youth mental healthcare from insurance companies to municipalities. While negotiations with insurers had posed challenges and caused market power imbalances, the shift to municipalities worsened the issue, increasing monopoly on the buyer side as well as transaction costs related to wider information asymmetries between municipal authorities and providers of specialized mental healthcare (Westra et al., 2016) Mondriaan's Child and Youth department, which had roughly $€ 15$ million in turnover during 2015, has been trying to rethink its value proposition for psychiatric services to adolescents, given the severe budget cuts over the past year. In October 2017, it was announced that Mondriaan will have to significantly downsize its child and youth department because of the unbearable workload on psychiatrist and nurses. In an interview with Dutch newspaper NRC, ${ }^{6}$ the organization declared "it is not possible to continue" and that families and caregivers of the share of the 500 children currently admitted for treatment at Mondriaan will be referred to other providers. This is the second provider that has decided to turn to interrupt the provision of child mental healthcare in a very short span of time. A few days before Mondriaan's announcement, the organization for child protection William Schrikker Groep in Dordrecht and surroundings declared that they were not in the financial condition to be able to continue offering their services, because the reimbursements are too low to maintain the necessary quality levels (Westra et al., 2016). For children of 300 families, it is not clear now what the future will hold in 2018. As the 
third example of the extreme challenges faced by Dutch mental healthcare organizations in comes from of Mondriaan's most prominent competitor, Virenze, which has very recently declared bankruptcy. ${ }^{7}$ Virenze's business model seemed initially better placed to respond to the newly introduced policy framework, because of its patient mix comprising of both complex and milder cases, which allowed a financially more sustainable balance between high margin/low complexity outpatient cases and lower margin/higher complexity inpatient treatments. However, the low reimbursements paid by municipalities for the youth segment and by insurance companies for the adult segments have been insufficient to ensure quality and to maintain productivity. Virenze served 10,000 patients and employed 465 professionals, which underlines the implosion the mental healthcare sector is facing. Also, a bankruptcy of this is considered an "exceptional case," as mostly financially fragile organizations with such a central societal responsibility are savaged through mergers with competitors.

\section{Conclusions}

At the core of any business and organization lies the concept of value, and any organization is unique in the type of configuration that allows it to deliver value to its customers and capture part of it for its own growth. This chapter delineated an understanding of the multifaceted concept of value in the case of healthcare delivery, characterized by multiple constituencies and by the rapidly evolving concept of health, from a purely medical view to a more encompassing state of wellbeing. Value-based healthcare is now a paradigm that guides and defines most policy reforms and organizational strategic choices in the healthcare sector, and provides an important framework of reference for any entrepreneurial venture in this domain. Against this backdrop, the lens of hybrid organizations enables focus on important challenges and complexities that healthcare ventures are bound to face: the ones related to the co-existence of multiple constituencies, often holding clashing claims-such as patients and insurance companies in the case of Dutch hospitals; or municipalities and youth patients, in the case of child and youth mental healthcare providers; and the ones pertinent to value that does not automatically spill over to the beneficiaries: the patients, as in the case of health-enhancing technologies among disadvantaged communities.

Being cognizant of these challenges provides an important starting point to devise appropriate strategies, commercial formulas to deliver valueperceived and internalized as such by the beneficiaries-and appropriate value to ensure sustainability, so that the needs of the various constituent groups are met. The healthcare entrepreneur is faced with a difficult, yet challenging, orchestration work, which can, however, unleash enormous impact for society and patients alike. 


\section{Notes}

1. PBS Newshour (2015). How this Indian medical chain makes heart surgery affordable. [video] Available at: https://www.youtube.com/watch?v=qaI5WBHV Gmo [Accessed 22 Apr. 2018].

2. PBS Newshour (2015). How this Indian medical chain makes heart surgery affordable. [video] Available at: https://www.youtube.com/watch?v=qaI5WBHV Gmo [Accessed 22 Apr. 2018].

3. GGZnieuwz (2015). At least 3000 young people with serious mental problems per year. Available at: https://www.ggznieuws.nl/home/minimaal-3000-jongeren met-ernstige-psychische-problemen-per-jaar/ [Accessed 22 Apr. 2018].

4. GGZnieuwz (2017). Young people wait a long time to find help with psychiatric disorders. Available at: https://www.ggznieuws.nl/home/jongerenwachten-lang-zoeken-hulp-psychiatrische-stoornissen/.

5. Nji.nl. (2018). Depression. Available at: https://www.nji.nl/nl/Databank/Cijfersover-Jeugd-en-Opvoeding/Cijfers-per-onderwerp/Cijfers-per-onderwerpDepressie.

6. Vriesema, I. (2017). Limburgse instelling staakt deel jeugd-ggz binnenkort. NRC. nl. Available at: https://www.nrc.nl/nieuws/2017/10/01/limburgse-instellingstaakt-deel-jeugd-ggz-binnenkort-13287294-a1575600.

7. Vriesema, I. (2017). Ggz-instelling Virenze failliet: gevolg voor patiënten ongewis. NRC.nl. Available at: https:/www.nrc.nl/nieuws/2017/12/19/ggz-instellingvirenze-failliet-gevolg-voor-patienten-ongewis-a1585603.

\section{References}

Angeli, F., and Jaiswal, A. K. 2015. Competitive dynamics between MNCs and domestic companies at the base of the pyramid: An institutional perspective. Long Range Planning, 48: 182-199.

Angeli, F., and Jaiswal, A. K. 2016. Business model innovation for inclusive health care delivery at the bottom of the pyramid. Organization and Environment, 29.

Arrow, K. J. 1963. Uncertainty and the welfare economics of medical care. The American Economic Review, 53: 141-149.

Banerjee, A. V., and Duflo, E. 2012. Poor Economics. London: Penguin Books.

Battilana, J., and Dorado, S. 2010. Building sustainable hybrid organizations: The case of commercial microfinance organizations. Academy of Management Journal, 53: 1419-1440.

Battilana, J., and Lee, M. 2014. Advancing research on hybrid organizingInsights from the study of social enterprises. The Academy of Management Annals, 8: 397-441.

Battilana, J., Sengul, M., Pache, A. C., and Model, J. 2015. Harnessing productive tensions in hybrid organizations: The case of work integration social enterprises. Academy of Management Journal, 58: 1658-1685.

Bonfrer, I., Figueroa, J. F., Zheng, J., Orav, E. J., and Jha, A. K. 2018. Impact of financial incentives on early and late adopters among US hospitals: Observational study. BMJ, 360: j5622.

Chisholm, D., Sweeny, K., Sheehan, P., Rasmussen, B., Smit, F., Cuijpers, P., and Saxena, S. 2016. Scaling-up treatment of depression and anxiety: A global return on investment analysis. The Lancet Psychiatry, 3: 415-424.

Das, M., Angeli, F., Krumeich, A. J. S. M., and van Schayck, O. C. P. 2018. Patterns of illness disclosure among Indian slum dwellers: A qualitative study. BMC International Health and Human Rights, 18. 
Donabedian, A. 1988. The quality of care: How can it be assessed? JAMA, 260: 1743-1748.

Dranove, D., and White, W. D. 1994. Recent theory and evidence on competition in hospital markets. Journal of Economics \& Management Strategy, 3: 169-209.

Fosfuri, A., Giarratana, M. S., and Roca, E. 2016. Social business hybrids: Demand externalities, competitive advantage, and growth through diversification. Organization Science, 27: 1275-1289.

Haigh, N., Walker, J., Bacq, S., and Kickul, J. 2015. Hybrid organizations: Origins, strategies, impacts, and implications. California Management Review, 57: 5-12.

Hannigan, B., and Coffey, M. 2011. Where the wicked problems are: The case of mental health. Health Policy, 101: 220-227.

Huber, M., Knottnerus, J. A., Green, L., van der Horst, H., Jadad, A. R., Kromhout, D., Leonard, B., Lorig, K., Loureiro, M. I., and van der Meer, J. W. M. 2011. How should we define health? BMJ: British Medical Journal, 343.

Kumar Rastogi, S. 2013. A Case Study of Sulabh International Social Service Organization. Retrieved from http://www.sulabhinternational.org/wp-content/ uploads/2015/07/SISSO-Case-Study-IIM-Ahmedabad.pdf

Larson, J. S. 1999. The conceptualization of health. Medical Care Research and Review, 56: 123-136.

Lewis, J. J., and Pattanayak, S. K. 2012. Who adopts improved fuels and cookstoves? A systematic review. Environmental Health Perspectives, 120: 637-645.

Mehrotra, K. 2014. India's Toilet Race Failing as Villages Don't Use Them. Retrieved from https://www.bloomberg.com/news/articles/2014-08-03/indias-toilet-race-failing-as-villages-don-t-use-them

Molodynski, A., Rugkåsa, J., and Burns, T. 2010. Coercion and compulsion in community mental health care. British Medical Bulletin, 95: 105-119.

Narayana Hrudayalaya Limited (2016). Annual Report Narayana Health. [online] Retrieved from https://www.narayanahealth.org/annual-report-2016. pdf [Accessed 22 Apr. 2018].

O'Reilly, K., and Louiss, E. 2014. The toilet tripod: Understanding successful sanitation in rural India. Health and Place, 29: 43-51.

Pache, A. C., and Santos, F. 2013. Inside the hybrid organization: Selective coupling as a response to competing institutional logics. Academy of Management Journal, 56.

Porter, M. E. 2010. What is value in health care? New England Journal of Medicine, 363: 2477-2481.

Porter, M. E., and Teisberg, E. O. 2004. Redefining competition in health care. Harvard Business Review: 64-77.

Santos, F., Pache, A.-C., and Birkholz, C. 2015. Making hybrids work. California Management Review, 57: 36-59.

Schut, F. T., and Varkevisser, M. 2017. Competition policy for health care provision in the Netherlands. Health Policy, 121(2): 126-133.

Teece, D. 2010. Business models, business strategy and innovation. Long Range Planning, 43: 172-194.

Tracey, P., and Jarvis, O. 2006. An enterprising failure: Why a promising social franchise collapsed. Stanford Social Innovation Review, 4: 66-70.

Vigo, D., Thornicroft, G., and Atun, R. 2016. Estimating the true global burden of mental illness. The Lancet Psychiatry, 3: 171-178. 
Westra, D., Angeli, F., Carree, M., and Ruwaard, D. 2015. Understanding competition between healthcare providers: Introducing an intermediary inter-organizational perspective. Health Policy, 121: 149-157.

Westra, D., Wilbers, G., and Angeli, F. 2016. Stuck in the middle? A perspective on ongoing pro-competitive reforms in Dutch mental health care. Health Policy, 120: 345-349.

World Health Organization. 2013. Mental Health Action Plan 2013-2020. WHO Library Cataloguing-in-Publication DataLibrary Cataloguing-in-Publication Data: 1-44.

World Health Organization. 2014. Progress on Drinking Water and Sanitation2014 Update; Joint Monitoring Programme for Water Supply and Sanitation. WHO Library Cataloguing-in-Publication DataLibrary Cataloguing-in-Publication Data: 1-78. 